\title{
NATURE CONSERVATION AND YOUTH SERVICE IN BRITAIN
}

$I^{\mathrm{N}}$ the past two reports of the National Parks Commission, appreciation has been expressed of the work done by volunteer groups in clearing disfigurements in the National Park areas in Perabrokeshire, Northumberland, the Lake District and the Peak District. When the Council for Nature was formed in 1958, it declared its intention of forming a volunteer group of young men and women to work in nature reserves and similar areas on tasks having the purpose of preserving the flora and fauna of the countryside. The Council's purpose in this project was twofold: on one hand, to help the many naturalists' trusts and other bodies in managing areas of scientific interest; and on the other, to offer young people in their spare time a task in the countryside which was worth while. This project was made possible by a generous grant from the Carnegie United Kingdom Trust, and in a paper read before Section $\mathrm{X}$ (Assembly of Corresponding Societies) of the British Association during the York meeting, Brigadier E. F. E. Armstrong, who has been responsible for the organization of this Volunteer Conservation Corps for the Council, described the scope of the Corps and some of the experience gained and problems encountered.

In contrast to the Civilian Conservation Corps of the United States, Brigadier Armstrong pointed out that the Conservation Corps is a volunteer sparetime activity, and the tasks undertaken had to be within the capacity of a group of young men and women working for the comparatively short periods they could give in holidays and vacations. Moreover, it was important that the task undertaken should have a viable ultimate scientific purpose, and should not be such that it would obviously be more usefully and efficiently done by machinery. Usually the tasks undertaken were those requiring manual rather than mechanical labour and suited to a group of volunteers, aged 16-23, working for periods of one, two or three weeks. In practice, the limiting factor had proved to be the financial resources, and not the availability of volunteers : some 400 volunteers had come forward against the 160 places that the Corps had been able to offer on 'residential' tasks, including week-end tasks and those occupying one or more weeks. Generally, the volunteers were from "sixth formers" of schools, but university undergraduates and older members of natural history societies; 'Rovers' and 'Rangers' had also been anxious to help.

For the most part, volunteers were educated and already interested in natural history, and leadership could be formed on the site of the work, though the responsibility for the prior organization of the work rested with the headquarters organizer and the members of the body for whom the work is being done.

Brigadier Armstrong stressed the educational side of the work. The programme always included a daily evening lecture on some topic of nature conservation, followed by discussion, and efforts were made to include a visit to some other site of scientific interest in the neighbourhood and to any Nature Conservancy or Forestry Commission establishment within range.
The education side had been much appreciated by the volunteers, and had clearly contributed to the success of the project. The Conservation Corps had already proved the existence of a very strong desire on the part of young men and women in Britain for an opportunity to assist in preserving the flora and fauna of the countryside.

Reference was made to the importance of satisfactory accommodation; for this year the Corps would have its own camp for a task exceeding a fortnight, while for other tasks accommodation had been obtained in youth hostels, a Field Studies Council hostel, a hotel and in H.M.S. Conway. Tasks already undertaken included clearing the dogwood. and other scrub which has invaded and is over. running the grassland slopes of Juniper Top, Boxhill ; clearance work in a compartment of Woodwalton Fen to open it up for fenland flora and improve it as a habitat for the large copper butterfly ; clearance of scrub in Askham Bog to show regeneration of plants and removing the top layer of vegetation to provide an area of more permanent bog conditions; clearing a path in Surlingham Broad to improve access to the centre of the Broad; and shelving down banks of ponds in Newborough Warren which had been excavated by machinery and planting suitable to consolidate these edges.

Brigadier Armstrong also referred to the development of week-end or single-day tasks, particularly in areas where plenty of volunteers are available and responsibility for organization could be delegated locally. Such tasks, which did not involve accommodation, were likely to be less expensive to organize and it was hoped to extend the development in future.

A following paper dealt with another problem also exercising concern both to the National Parks Commission and the Nature Conservancy. Breaches of the Country Code, damage to farm-land and in nature reserves is frequently done by teenagers from the big cities, seeking freedom from restrictions in the country and unaware of the dangers they them. selves often run or the damage they do. Mrs. Edie J. Green, senior instructor of the Kyndwr Scwd Mountain Training Centre, Derbyshire, described a successful attempt to enlist the adventurous spirit of a group of such boys and to guide it into useful purposes. A start was made with a group of eight boys drawn both from those full of enthusiasm for outdoor activities but lacking skilled guidance, and from those responsible for vandalism, usually through sheer exuberance rather than deliberate destructiveness. Following essentially the principles laid down in another sphere by Elton Mayo and Mary Follett, and applied so strikingly by Lieut.-Commander A. H. Leighton in a Japanese re-location camp, the friendship of the boys was first won, and also the co-operation and goodwill of farmers and others in the district with whom the schem $\theta$ would involve contact were secured. Then the boys were encouraged to frame their own rules and ultimately they produced a set of rules for the situation more impressive than the Country Code itself, breach of which was 
punished, by the group's own decision, by sending the offender home. In practice, the rules were rarely broken, because to the boys they made sense.

From this it was an easy step to the acceptance of the Country Code itself, and the boys were often heard talking to their contemporaries about what should or should not be done in the country; and Mrs. Green suggested very reasonably that this is likely to have a far deeper effect than police warnings or slogans on the notice boards. With this went a changed attitude to farmers. Getting to know the farmers and understanding what farming meant changed the attitude of the boys into one of respect and co-operation: the farmer who had provided the site for the camp found his shippen cleaned out for him and a boy who admitted to knocking down dry-stone walls for years was found attempting to rebuild one.
Such changes alone would justify the continuance of such training camps from the point of view of the national parks and nature reserves alone, but the scheme also provided a definite programme for training the boys in climbing, in mountain rescue and in first-aid-at their own request. Here again the boys, from being a liability or a nuisance on the hills, became competent members of a mountain rescue team, and every challenge to endurance was met with enthusiasm. The experimental period described by Mrs. Green also showed the value of the scheme in developing the personalities of the boys. Much clearly depends on the quality of the staff, and there is also the matter of equipment; but the now training centre which opened in September 1959 offers a first-class mountaineering course for $5 s$. affiliation fee and $2 s$. $6 d$. at each school, and thirty boys are being taken.

\section{APPLIED MATHEMATICS AND THEORETICAL PHYSICS AT CAMBRIDGE}

\begin{abstract}
A DEVELOPMEN'T in the University of Cambridge which will be of interest generally is the formation, from October I, 1959, of a Department of Applied Mathematics and Theoretical Physics. The Department comes within the Faculty of Mathe. matics, and embraces the present teaching staff and research students on the applied side of the Faculty. Academic staff at Cambridge traditionally divide their time between centralized university lecturing and supervision of research students (as university lecturers, readers, etc.) on one hand, and informal teaching of undergraduates in their own college (as Fellows) on the other. This arrangement undoubtedly has advantages for undergraduates, but it has not been without some unfortunate consequences for research in a number of subjects. The various colleges provide their official Fellows with rooms, and the existence of this accommodation has retarded the development of centralized departments and buildings with adequate facilities for research. Teaching and research in the experimental sciences are impossible without a properly equipped laboratory, and these subjects were the first to be provided with central University buildings. Less obvious perhaps, but no less real, is the need for theoreticians to meet and work together in these days of rapid scientific developments and enlarging horizons. The formation of a Department of Applied Mathematics and Theoretical Physics at Cambridge is a recognition of this need, and is viewed as an administrative step towards the provision of central office accommodation and research facilities for the members of the Department. When that is achieved, an anomaly peculiar to the University of Cambridge will have been removed.
\end{abstract}

There are two novel features of the new Department. The first is that, as implied by the name, the Department includes both 'classical' and 'modern' aspects of theoretical physics and engineering science, in contrast to the usual plan in which applied mathematics and theoretical physics fall in separate university departments. This unity was suggested by the existing practice of teaching both applied mathematies and theoretical physics in the Mathematical Tripos; and it was in any event felt to be appropriate. The customary division between applied mathematics and theoretical physics is scientifically rather arbitrary (being prompted, perhaps, by the fact that in most universities applied mathematics is linked with pure mathematics and theoretical physics with physics) and is often unfortunate in its effects. Recent work on plasma physics and magneto-gasdynamics has shown how much the two subjects have in common and how artificial is the division between them; and the older fields of theoretical astronomy and astrophysics have long illustrated the same point. The staff at Cambridge who will comprise the new Department are eighteen in number, and are engaged on work in elementary particle and field theory, nuclear physics, astrophysics, plasma dynamics, fluid mechanies and geophysics.

The second novel feature is the provision that the head of the Department shall be appointed for five years at a time from among the more senior people in the Department. This represents a deliberate departure from the practice in British universities of having a head with life tenure, usually the sole professor, or, where there is more than one professor, the one of greatest scientific distinction, and is more like the arrangement in many American universities. The disadvantages and risks of having a permanent head are well known; the health and fate of the department are tied to the administrative ability and capacity for leadership of one person for many years, the growth of a hierarchial structure may be encouraged, the talents of a rising leader may not be given full scope, and so on. There are also advantages, which may be more important in some circumstances; but there was a strong feeling at Cambridge that a more flexible scheme was desirable for the new Department. A period of five years was chosen as being long enough to allow the head of the Department to formulate and carry through any schemes which may be close to his heart, and short enough to be regarded as only a temporary interruption of personal research. The regulations allow re-appointment of a person for further periods of five years. This experiment in administration of a university department will be interesting and may have its lessons for other departments.

The first head of the Department is Dr. G. K. Batchelor, reader in fluid mechanics. He is known 